\title{
The Clinical Presentation of Puumala Hantavirus Induced Hemorrhagic Fever with Renal Syndrome Is Related to Plasma Glucose Concentration
}

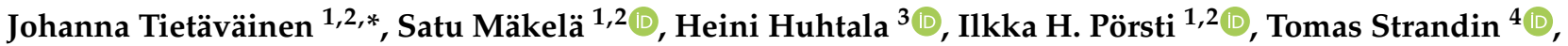 \\ Antti Vaheri ${ }^{4}$ and Jukka Mustonen ${ }^{1,2}$ \\ 1 Faculty of Medicine and Health Technology, Tampere University, 33520 Tampere, Finland; \\ satu.m.makela@pshp.fi (S.M.); ilkka.porsti@tuni.fi (I.H.P.); jukka.mustonen@tuni.fi (J.M.) \\ 2 Department of Internal Medicine, Tampere University Hospital, 33520 Tampere, Finland \\ 3 Faculty of Social Sciences, Tampere University, 33520 Tampere, Finland; heini.huhtala@tuni.fi \\ 4 Department of Virology, Medicum, University of Helsinki, 00290 Helsinki, Finland; \\ tomas.strandin@helsinki.fi (T.S.); antti.vaheri@helsinki.fi (A.V.) \\ * Correspondence: johanna.tietavainen@tuni.fi
}

check for

updates

Citation: Tietäväinen, J.; Mäkelä, S.; Huhtala, H.; Pörsti, I.H.; Strandin, T.; Vaheri, A.; Mustonen, J. The Clinical Presentation of Puumala Hantavirus Induced Hemorrhagic Fever with Renal Syndrome Is Related to Plasma Glucose Concentration. Viruses 2021, 13, 1177. https://doi.org/10.3390/ v13061177

Academic Editor: Artur Summerfield

Received: 11 May 2021

Accepted: 15 June 2021

Published: 20 June 2021

Publisher's Note: MDPI stays neutral with regard to jurisdictional claims in published maps and institutional affiliations.

Copyright: (c) 2021 by the authors. Licensee MDPI, Basel, Switzerland. This article is an open access article distributed under the terms and conditions of the Creative Commons Attribution (CC BY) license (https:/ / creativecommons.org/licenses/by/ $4.0 /)$.

\begin{abstract}
Puumala hantavirus (PUUV) causes a hemorrhagic fever with renal syndrome characterized by thrombocytopenia, increased capillary leakage, and acute kidney injury (AKI). As glucosuria at hospital admission predicts the severity of PUUV infection, we explored how plasma glucose concentration associates with disease severity. Plasma glucose values were measured during hospital care in 185 patients with PUUV infection. They were divided into two groups according to maximum plasma glucose concentration: P-Gluc $<7.8 \mathrm{mmol} / \mathrm{L}(n=134)$ and P-Gluc $\geq 7.8 \mathrm{mmol} / \mathrm{L}(n=51)$. The determinants of disease severity were analyzed across groups. Patients with P-Gluc $\geq 7.8 \mathrm{mmol} / \mathrm{L}$ had higher hematocrit $(0.46$ vs. $0.43 ; p<0.001)$ and lower plasma albumin concentration $(24 \mathrm{vs} .29 \mathrm{~g} / \mathrm{L}$; $p<0.001)$ than patients with P-Gluc $<7.8 \mathrm{mmol} / \mathrm{L}$. They presented with higher prevalence of pulmonary infiltrations and pleural effusion in chest radiograph, higher prevalence of shock and greater weight change during hospitalization. Patients with P-Gluc $\geq 7.8 \mathrm{mmol} / \mathrm{L}$ were characterized by lower platelet count (50 vs. $\left.66 \times 10^{9} / \mathrm{L} ; p=0.001\right)$, more severe AKI (plasma creatinine 272 vs. $151 \mu \mathrm{mol} / \mathrm{L} ; p=0.001$ ), and longer hospital treatment (8 vs. 6 days; $p<0.001$ ) than patients with P-Gluc $<7.8 \mathrm{mmol} / \mathrm{L}$. Plasma glucose level is associated with the severity of capillary leakage, thrombocytopenia, inflammation, and AKI in patients with acute PUUV infection.
\end{abstract}

Keywords: puumala hantavirus; hyperglycemia; capillary leakage; thrombocytopenia; AKI; endothelial damage

\section{Introduction}

Hantaviruses cause two clinical disease entities. Hemorrhagic fever with renal syndrome (HFRS) found in Eurasia is caused by Hantaan, Puumala and Dobrava viruses. Hantavirus cardiopulmonary syndrome (HCPS) present in the Americas is caused by Sin Nombre, Andes and related hantaviruses. Seoul virus that causes HFRS is found worldwide [1].

Puumala virus (PUUV) is the only human pathogenic hantavirus in Finland. It is a member of the Orthohantavirus genus in the Hantaviridae family, order Bunyavirales and it is carried by the bank vole (Myodes glareolus). PUUV-induced HFRS is characterized by thrombocytopenia, increased capillary leakage, and acute kidney injury (AKI).

The clinical picture of PUUV infection varies from asymptomatic infection to severe disease, but most cases have a mild course. In typical forms of infection, five distinct phases can be recognized: febrile, hypotensive, oliguric, polyuric and convalescent. Patients usually arrive at the hospital at the hypotensive phase when capillary leakage prevails. Patients may have pulmonary infiltrations and pleural effusion, pericardial effusion, and 
retroperitoneal edema [1]. Of the hospitalized patients, less than $5 \%$ have circulatory shock. As markers of renal involvement, most patients have transient proteinuria and hematuria. The hypotensive phase is followed by oliguria and AKI. About $6 \%$ need transient dialysis treatment. Polyuria, that can be substantial, is a sign of recovery [2]. Bleeding diathesis is rare and case fatality is less than $0.5 \%$ [2]. Host genetic factors influence the clinical course of the disease [3].

The impact of hyperglycemia on the outcome of hospitalized patients has been studied in various diseases. It is currently appreciated that hyperglycemia, whether critical illness induced or related to diabetes, is associated with poor outcome in severely ill patients $[4,5]$. In diabetic SARS-CoV2 patients, poorly controlled glycemic variability is associated with higher mortality as well as with higher incidence of AKI, septic shock, acute respiratory distress syndrome (ARDS) and disseminated intravascular coagulation (DIC) [6,7]. Interestingly, fasting blood glucose at admission in COVID-19 patients without previous diagnosis of diabetes is also an independent predictor for 28-day mortality in a multi-center retrospective study [7].

There is a growing body of evidence showing that acute hyperglycemia in nondiabetic patients is related to kidney injury. In patients with acute myocardial infarction, admission hyperglycemia is associated with AKI [8]. In an experimental animal model, 6-h glucose infusion caused structural and functional changes in kidney glomeruli and tubular epithelial cells, and induced structural changes in small vessels [9]. Of these, renal tubular injury appeared to be most prominent. In addition, transient hyperglycemia induced inflammation, oxidative stress and apoptosis [9].

Recently we reported that $12 \%$ of patients with PUUV infection have mild and transient glucosuria on admission to hospital. Glucosuria is associated with more severe thrombocytopenia and inflammation, as well as with higher capillary leakage and more severe AKI [10]. Histologically PUUV causes acute tubulointerstitial nephritis (ATIN), and therefore we hypothesized that more severe ATIN impaired glucose reuptake in the proximal tubule of the kidney resulting in glucosuria [10]. In that study, blood glucose concentration was slightly higher in the glucosuric patients, but in the majority of patients, it was below the kidney glucose threshold level [10]. This finding led us to investigate the association of blood glucose level with the severity of PUUV infection.

We analyzed the outcome of patients grouped according to the maximum plasma glucose concentration of either $<7.8 \mathrm{mmol} / \mathrm{L}$ or $\geq 7.8 \mathrm{mmol} / \mathrm{L}$ during hospital treatment. According to our results, plasma glucose concentration is associated with all the known determinants of disease severity of acute PUUV infection. In addition, markers of increased capillary leakage and levels of thrombocytopenia and leukocytosis are associated dose dependently with maximum plasma glucose level.

\section{Materials and Methods}

\subsection{Subjects}

The study cohort included 185 adult patients treated in Tampere University Hospital, Finland, due to serologically confirmed acute PUUV infection during the years 1986-2017. Information of plasma glucose level during hospital care was collected retrospectively. Analyses of plasma glucose concentrations during hospital treatment were based on clinical relevance. One glucose value was found for 127 patients, two for 39 patients, and 3-10 values for 19 patients.

A detailed medical history of the patients was obtained, and all patients were carefully clinically examined. Blood pressure, heart rate and weight were measured at least daily. The daily urine output was followed during the hospital stay.

Out of the 185 patients, $69(37 \%)$ had one or several previous diagnoses: hypertension $(n=19)$, hypercholesterolemia $(n=8)$, type 2 diabetes $(n=6)$, cardiac arrhythmia/conduction disturbance $(n=6)$, coronary heart disease $(n=4)$, rheumatoid arthritis $(n=3)$, coeliac disease $(n=3)$, operated malignancy $(n=3)$, prostate hyperplasia $(n=2)$, osteoporosis $(n=2)$, psoriasis $(n=2)$, and mental illness $(n=2)$. In addition, the fol- 
lowing diagnoses were present in one patient each: hyperthyroidism, hypothyroidism, cerebral infarction, juvenile rheumatoid arthritis, Sjögren's syndrome, spondyloarthropathy, Crohn's disease, epilepsy, sarcoidosis, idiopathic thrombocytopenia, bronchial asthma and spherocytosis. One patient was pregnant, and one was breastfeeding. One patient was diagnosed with type two diabetes during hospital care. None of the patients had a known chronic kidney disease before the PUUV infection. Three patients used metformin prior to hospitalization and two patients received insulin during hospital treatment.

A chest radiograph was taken from 75/185 (41\%) patients at hospital admission. Radiographs were analyzed by one radiologist for the presence or absence of pulmonary infiltrations or pleural effusion [11]. Chest radiographs were graded as normal, or as having mild, moderate or severe changes as described by Paakkala et al. [11].

Shock was defined as having systolic blood pressures of under $90 \mathrm{mmHg}$ and clinical symptoms of shock such as pale, cold, or clammy skin, rapid breathing, and rapid heartbeat.

All patients provided a written informed consent, and the study with its extensions was approved by the Ethics Committee of the Tampere University Hospital (study codes 97166, 99256, R04180, R15007 and R09206).

\subsection{Laboratory Determinations}

The diagnosis of PUUV infection was made by detecting the typical granular staining pattern of acute infection and/or low avidity of IgG antibodies in immunofluorescence using PUUV -infected Vero E6 cells as antigens, and/or by detecting PUUV IgM antibodies by an "in-house" enzyme-linked immunosorbent assay based on baculovirus-expressed PUUV nucleocapsid protein. The development and use of the above and diagnostic methods have been described elsewhere [12].

Type 2 diabetes is diagnosed based on increased concentration of glycated hemoglobin (HbA1c), fasting plasma glucose, or 2-h postprandial plasma glucose. According to the American Diabetes Association (ADA) and World Health Organization (WHO) criteria, P-Gluc $<7.8 \mathrm{mmol} / \mathrm{L}$ is normal in oral glucose tolerance test, P-Gluc 7.8-11.0 mmol/L corresponds to impaired glucose tolerance and P-Gluc $>11.0 \mathrm{mmol} / \mathrm{L}$ is diabetic. Random glucose value of $>11 \mathrm{mmol} / \mathrm{L}$ in a symptomatic patient is diagnostic for diabetes [13]. There are no reference values of what constitutes hyperglycemia during acute illness. For the purpose of the present study, random glucose value $<7.8 \mathrm{mmol} / \mathrm{L}$ during hospital care was considered normoglycemic, and random glucose level $\geq 7.8 \mathrm{mmol} / \mathrm{L}$ was considered hyperglycemic.

Blood glucose was analyzed from whole blood samples and reported as blood glucose (mmol/L) until August 2003, and as plasma glucose (mmol/L) thereafter. For the analyses, blood glucose values were converted to plasma glucose values by multiplying the blood glucose values by 1.11 [14]. The highest plasma glucose value measured during the hospital treatment was chosen for the analysis, regardless of how many samples per patient were available.

Plasma creatinine was analyzed by Vitros (Johnson \& Johnson, Rochester, NY, USA) until the year 1999 and by Cobas Integra (F. Hoffmann-La Roche Ltd., Basel, Switzerland) from thereafter. Blood cell count was determined by automated hematological cell counters (Bayer Diagnostics, Elkhart, IN, USA) and albumin concentrations using routine automated chemistry analyzers. All laboratory determinations were performed by the Laboratory Centre of the Pirkanmaa Hospital District (later named Fimlab laboratories), Tampere, Finland.

Plasma creatinine, C-reactive protein (CRP) and blood count including hematocrit, leukocytes and platelets were measured in $96 \%-100 \%$, and plasma albumin in $48 \%$ of the study subjects. Information on body mass index (BMI) and shock was available from $70 \%$ and $90 \%$ of the patients, respectively. Minimum or maximum of the values were used in the statistical analysis as indicated in Tables 1 and 2. 
Table 1. Clinical findings in 185 patients with PUUV infection according to maximum plasma glucose concentration.

\begin{tabular}{|c|c|c|c|c|c|}
\hline \multirow[b]{2}{*}{ Plasma and Blood Findings } & \multicolumn{2}{|c|}{$\begin{array}{c}\text { Plasma Glucose }<7.8 \mathrm{mmol} / \mathrm{L} \\
n=134\end{array}$} & \multicolumn{2}{|c|}{$\begin{array}{c}\text { Plasma Glucose } \geq 7.8 \mathrm{mmol} / \mathrm{L} \\
n=51\end{array}$} & \multirow[b]{2}{*}{$p$-Value } \\
\hline & Median/Number & Range/\% & Median/Number & Range/\% & \\
\hline Age (years) & 40 & $18-77$ & 48 & $25-69$ & 0.003 \\
\hline Male/female * & $90 / 44$ & $73 / 71$ & $33 / 18$ & $27 / 29$ & $0.862 \ddagger$ \\
\hline Diabetes & $0 / 134$ & 0 & $7 / 51$ & 14 & $<0.001+$ \\
\hline BMI & 24.8 & $19.8-35.8$ & 27.3 & $21.0-37.2$ & 0.005 \\
\hline Shock $\tau$ & $2 / 119$ & 2 & $7 / 46$ & 15 & $0.002+$ \\
\hline Systolic BP initial (mmHg) & 124 & $90-210$ & 125 & $60-180$ & 0.594 \\
\hline Diastolic BP initial (mmHg) & 80 & 30-105 & 78 & $30-110$ & 0.772 \\
\hline Min systolic BP (mmHg) & 116 & $87-170$ & 110 & $60-150$ & 0.010 \\
\hline Min diastolic BP (mmHg) & 72 & $46-100$ & 69 & 36-95 & 0.044 \\
\hline Weight change $(\mathrm{kg}) \sim$ & 2.6 & $0.1-10.1$ & 4.8 & $0.5-18.5$ & $<0.001$ \\
\hline Dialysis & $4 / 119$ & 3 & $5 / 45$ & 11 & $0.116+$ \\
\hline $\begin{array}{l}\text { Pulmonary infiltrations in chest radiograph } \\
\text { (normal/mild/moderate) }\end{array}$ & $37 / 20 / 0$ & $65 / 35 / 0$ & $7 / 9 / 2$ & $39 / 50 / 11$ & $0.019+$ \\
\hline Pleural effusion in chest radiograph & $15 / 57$ & 26 & $10 / 18$ & 56 & $0.024+$ \\
\hline Hospital stay (days) & 6 & $1-20$ & 8 & $3-30$ & $<0.001$ \\
\hline
\end{tabular}

* Number or percentage within sex. $\ddagger$ Pearson Chi-Square; † Fisher's exact test, all others Mann-Whitney U test. $\tau$ Shock defined as systolic blood pressure $<90 \mathrm{mmHg}$ and symptoms of a shock. Difference between highest and lowest weight during hospital care reflecting both capillary leakage and fluid accumulation during oliguric phase. BMI, body mass index; BP, blood pressure.

Table 2. Laboratory findings in 185 patients with PUUV infection according to maximum plasma glucose concentration.

\begin{tabular}{|c|c|c|c|c|c|}
\hline \multirow[b]{2}{*}{ Plasma and Blood Findings } & \multicolumn{2}{|c|}{ Plasma Glucose $<7.8 \mathrm{mmol} / \mathrm{L}$} & \multicolumn{2}{|c|}{ Plasma Glucose $\geq 7.8 \mathrm{mmol} / \mathrm{L}$} & \multirow[b]{2}{*}{$p$-Value } \\
\hline & Median & Range & Median & Range & \\
\hline Glucose max (mmol/L) & 6.2 & $4.2-7.7$ & 9.3 & $7.8-34.1$ & $<0.001$ \\
\hline Glucose min (mmol/L) & 5.9 & $4.0-7.7$ & 7.4 & $4.4-34.1$ & $<0.001$ \\
\hline Glucose arrival (mmol/L) & 6.2 & $4.0-7.7$ & 8.7 & $6.1-34.1$ & $<0.001$ \\
\hline Platelets $\min \left(\times 10^{9} / \mathrm{L}\right)$ & 66 & $3-293$ & 50 & $4-249$ & 0.001 \\
\hline Hematocrit max & 0.43 & $0.34-0.58$ & 0.46 & $0.32-0.66$ & $<0.001$ \\
\hline Albumin min $(\mathrm{g} / \mathrm{L})$ & 29 & $21-43$ & 24 & $11-33$ & $<0.001$ \\
\hline Leukocytes $\max \left(\times 10^{9} / \mathrm{L}\right)$ & 9.6 & $4.6-22.8$ & 13.0 & $5.1-45.0$ & $<0.001$ \\
\hline $\mathrm{CRP} \max (\mathrm{mg} / \mathrm{L})$ & 74 & 9-305 & 79 & $19-214$ & 0.157 \\
\hline Creatinine $\max (\mu \mathrm{mol} / \mathrm{L})$ & 151 & $58-1156$ & 272 & 71-1499 & 0.001 \\
\hline
\end{tabular}

CRP, C-reactive protein.

\subsection{Statistical Analysis}

The data are presented as medians and ranges for continuous variables and numbers and percentages for categorical variables. Groups were compared using the KruskalWallis test or Mann-Whitney U test, as appropriate. Bonferroni correction for multiple comparisons was applied in the post-hoc analyses. The Chi-square or Fisher's exact tests were used to examine differences in proportions. Spearman correlations $\left(\mathrm{r}_{\mathrm{S}}\right)$ was used to study the relationship between continuous variables. Multivariate linear regression analyses were performed, taking variables reflecting disease severity (maximum blood hematocrit, leukocytes and CRP, and minimum blood platelet and plasma albumin level, as well as change in weight and duration of hospital stay) as dependent variables, and taking maximum plasma glucose value, BMI, age and sex as independent variables. All analyses were performed using IBM SPSS Statistics version 25 (IBM, Armonk, NY, USA).

\section{Results}

\section{Clinical, Laboratory and Radiological Findings}

Out of 185 patients 134 had maximum plasma glucose $<7.8 \mathrm{mmol} / \mathrm{L}$ and in 51 patients this was $\geq 7.8 \mathrm{mmol} / \mathrm{L}$ (Tables 1 and 2). All type 2 diabetic patients were included in the hyperglycemic group $(7 / 51,14 \%)$. Plasma glucose concentration peaked at median day 
5 (range 1-25 days) after the onset of first symptom i.e., fever. Two thirds of the patients were men, but the sex distribution did not differ between the groups. Hyperglycemic patients were slightly older and more overweight than normoglycemic patients (Table 1). There was no difference in BMI between the sexes (median BMI of 25.1 for men and 24.9 for women, $p=0.917$ ). Upon arrival to the hospital, hyperglycemic patients were more often in shock and they had lower minimum systolic and diastolic blood pressure during hospital care. In addition, they had a greater change in weight and their treatment time at the hospital was longer (Table 1).

Chest radiographs showed pulmonary infiltrations and pleural effusion more often in patients with hyperglycemia compared to those with normoglycemia (Table 1).

As laboratory markers of increased capillary leakage, hyperglycemic patients had higher maximum hematocrit and lower plasma albumin level than normoglycemic patients. Hyperglycemic patients had more severe thrombocytopenia and higher blood leukocyte count, but the maximum CRP value did not differ between the groups (Table 2).

Hyperglycemic patients had higher maximum plasma creatinine concentration than normoglycemic patients (Table 2). They had glucosuria more often in a dipstick urine test at hospital admission ( $31 \%$ vs. $5 \% ; p<0.001)$, but there were no differences in the results of dipstick tests for albuminuria and hematuria between the groups (data not shown).

The results remained the same when the seven diabetics in the hyperglycemic group were excluded from the analysis (data not shown).

Plasma glucose level correlated with BMI $\left(\mathrm{r}_{\mathrm{S}} 0.278, p=0.001\right)$, as did many variables reflecting disease severity (Table 3 ). In multivariate linear regression analysis with maximum plasma glucose concentration, BMI, age, and sex as independent variables, all of the main laboratory variables reflecting disease severity were associated with maximum plasma glucose concentration (Table 4). In contrast, the variables reflecting disease severity were not associated with BMI, age or sex (Supplementary Tables S1-S7).

Table 3. Correlation coefficients of variables reflecting disease severity with maximum plasma glucose and body mass index (BMI).

\begin{tabular}{|c|c|c|c|c|}
\hline & $\begin{array}{l}\text { Correlation Coefficient for } \\
\text { Maximum Plasma Glucose }\end{array}$ & $p$-Value & $\begin{array}{c}\text { Correlation } \\
\text { Coefficient for BMI }\end{array}$ & $p$-Value \\
\hline Platelets $\min \left(\times 10^{9} / \mathrm{L}\right)$ & -0.307 & $<0.001$ & 0.085 & 0.130 \\
\hline Hematocrit max & 0.369 & $<0.001$ & 0.153 & 0.006 \\
\hline Albumin min $(\mathrm{g} / \mathrm{L})$ & -0.375 & $<0.001$ & -0.121 & 0.150 \\
\hline Leukocytes $\max \left(\times 10^{9} / \mathrm{L}\right)$ & 0.262 & $<0.001$ & 0.094 & 0.094 \\
\hline $\mathrm{CRP} \max (\mathrm{mg} / \mathrm{L})$ & 0.201 & 0.007 & 0.166 & 0.003 \\
\hline Weight change (kg) & 0.316 & $<0.001$ & 0.095 & 0.096 \\
\hline Hospital stay (days) & 0.296 & $<0.001$ & -0.017 & 0.763 \\
\hline
\end{tabular}

Spearman's correlations. CRP, C-reactive protein.

When grouping the patients in quartiles of maximum plasma glucose concentration, an apparent dose dependency in relation to the markers of increased capillary leakage, lowest thrombocyte count, and leukocytosis was observed (Figure 1A-E). However, the association of maximum plasma glucose with highest plasma creatinine was more complex: a significant difference was observed between the second and the fourth quartile, while the lowest maximum plasma glucose quartile presented with corresponding creatinine values to the highest fourth quartile (Figure 1F). 
Table 4. Multivariate linear regression analysis for disease severity outcomes, dependent of maximum plasma glucose concentration.

\begin{tabular}{ccccc}
\hline & \multicolumn{4}{c}{ Maximum Plasma Glucose } \\
\hline & B & SE & Beta & $p$-Value \\
\hline Platelets min $\left(\times 10^{9} / \mathrm{L}\right)$ & -4.083 & 1.390 & -0.251 & 0.004 \\
Hematocrit max & 0.006 & 0.002 & 0.270 & 0.002 \\
Albumin min $(\mathrm{g} / \mathrm{L})$ & -0.580 & 0.181 & -0.374 & 0.002 \\
Leukocytes max $\left(\times 10^{9} / \mathrm{L}\right)$ & 0.931 & 0.209 & 0.378 & 0.000 \\
CRP max $(\mathrm{mg} / \mathrm{L})$ & 3.073 & 1.731 & 0.160 & 0.078 \\
Weight change $(\mathrm{kg})$ & 0.323 & 0.094 & 0.308 & 0.001 \\
Hospital stay (days) & 0.322 & 0.106 & 0.269 & 0.003 \\
\hline
\end{tabular}

$\mathrm{SE}$, standard error of the mean; CRP, C-reactive protein.
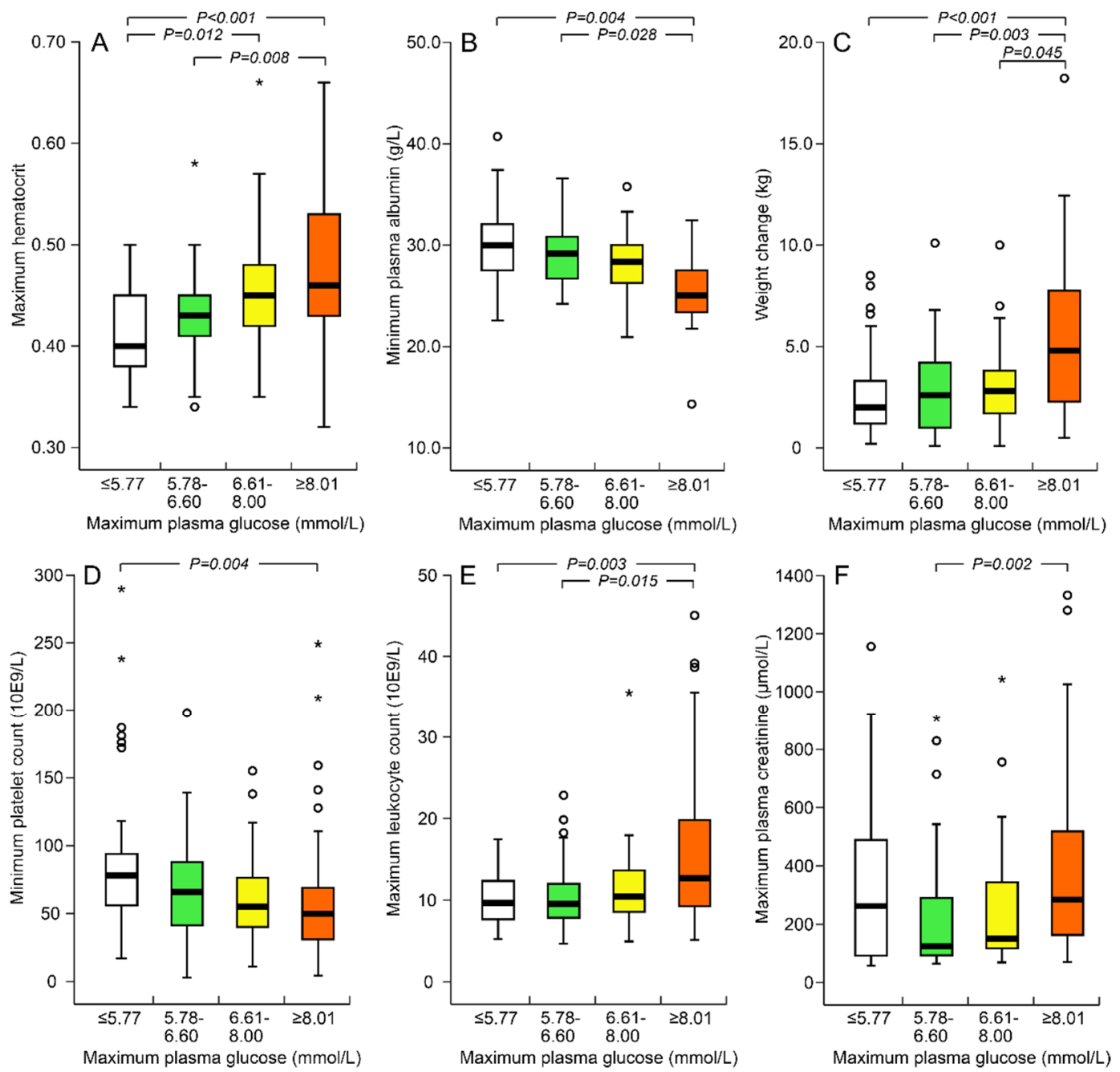

Figure 1. Maximum hematocrit (A), minimum plasma albumin (g/L) (B), weight change during hospital care (kg) (C), minimum platelet count $\left(\times 10^{9} / \mathrm{L}\right)(\mathbf{D})$, maximum blood leukocytes $\left(\times 10^{9} / \mathrm{L}\right)(\mathrm{E})$ and maximum plasma creatinine $(\mu \mathrm{mol} / \mathrm{L})$ (F) as grouped according to quartiles of maximum plasma glucose concentration. Boxplots with median, interquartile range, minimum and maximum within 1.5 interquartile range, and outliers displayed as circles and extreme values as asterisks. Bonferroni correction for multiple comparisons was applied in the post-hoc analyses. 


\section{Discussion}

In this study, we found for the first time that plasma glucose level was associated with disease severity in patients with acute hantavirus infection. Maximum plasma glucose was related to the clinical, laboratory and radiological markers of increased capillary leakage, and with thrombocytopenia, leukocyte count, and AKI. The present study follows our recent report, in which we found that dipstick glucosuria on admission to hospital predicted a severe course of PUUV infection [10]. Interestingly, our finding on the significance of glucosuria was recently replicated in COVID-19 patients [15].

All patients in the group with plasma glucose $<7.8 \mathrm{mmol} / \mathrm{L}$ were non-diabetics, while only $14 \%$ of patients with plasma glucose $\geq 7.8 \mathrm{mmol} / \mathrm{L}$ were diabetics. We cannot exclude the possibility that some of the patients may have had an underlying impairment in glucose metabolism or undiagnosed diabetes. Nevertheless, a clear difference was detected when patients were grouped according to plasma glucose concentration. In addition, hospitalized patients with PUUV infection often have nausea and vomiting which may have equalized differences in plasma glucose concentration between severely ill and milder cases.

Hyperglycemia in severely ill, non-diabetic patients is believed to be caused by the cytokines (interleukin (IL)-1 $\beta$ and tumor necrosis factor (TNF)- $\alpha$ ) that induce insulin resistance, and by hepatic gluconeogenesis driven by glucagon, catecholamines, cortisol, and growth hormone [16]. In PUUV infection, cortisol level is upregulated in the acute phase [17], but according to our unpublished observations, cortisol level does not associate with plasma glucose level in this disease.

Interestingly, it was recently shown in mice that viral infection with murine cytomegalovirus (MCMV), influenza A (INFA) virus and lymphocytic choriomeningitis virus (LCMV) induce production of interferon gamma (IFN- $\gamma$ ) by natural killer (NK) cells, which downregulates insulin receptor transcription in skeletal muscle, causing insulin resistance without glucose elevation [18]. Insulin resistance is compensated by increased pancreatic insulin production, thus preserving glycemic control. The resulting hyperinsulinemia boosts $\mathrm{CD} 8^{+} \mathrm{T}$-cell mediated antiviral response. However, in obese, pre-diabetic mice compensatory mechanisms are overloaded, and long-term loss of glycemic control ensues. This mechanism links the immune and the endocrine systems [18]. Whether the observed hyperglycemia during acute PUUV infection actually reflects the extent of hyperinsulinemia, which then could be at least partially responsible for the well-documented $\mathrm{CD}^{+}$T-cell responses during acute PUUV infection [19], remains to be determined.

SARS-CoV-1 is known to induce hyperglycemia by causing dysfunction in pancreatic islet cells [20]. Middle Eastern Respiratory Syndrome (MERS) coronavirus is anchored to host cells via dipeptidyl peptidase-4 (DPP-4) [21] which is responsible for the degradation of incretins such as glucagonlike peptide-1 (GLP-1). In influenza A infection, elevated inflammatory cytokine expression levels are tightly correlated with high levels of blood glucose [22]. Pancreatic enlargement has been detected in SARS-CoV-2 infected patients possibly affecting insulin production and causing hyperglycemia in non-diabetic patients [23]. Thus, multiple mechanisms of virus-induced hyperglycemia exist.

It is currently not known, what causes the glucose elevation in PUUV infection. Similarly to MCMV, INFA and LCMV infections [18,22], cytokine induced insulin resistance and hormonal changes [16] are possible. PUUV infects tissues throughout the body. Although infection induced pancreatitis is usually not detected [24], the possibility of infection induced changes in insulin production cannot be excluded. Like PUUV, LCMV and Ljunganvirus (also called Parechovirus B) use bank vole as a reservoir, and Ljungan virus induces pancreatic islet autoantibody production $[25,26]$. Sequential or co-infection of PUUV with either one of the two viruses might therefore result in changes in glucose metabolism [26]. Direct molecular mechanisms, as in coronavirus infections, are currently unknown.

In our study, plasma glucose concentration related to the severity of capillary leakage and thrombocytopenia. It is possible, that higher plasma glucose concentration is merely a sign of more severe disease during PUUV infection. However, plasma glucose may also influence the pathophysiological process of PUUV infection by damaging vascular 
endothelium. Septic bacterial infection and hyperglycemia are known to associate with loss of endothelial glycocalyx, the mechanism of which contributes to vascular dysfunction and coagulation activation [27-29]. Sepsis leads to ubiquitous degradation of the glycocalyx, altered endothelial permeability with hypovolemia, hypoalbuminemia, and edema. Several inflammatory mediators are implicated in the pathophysiology and glycocalyx shedding is worsened by hyperglycemia [29]. In mice, short-term hyperglycemia increases permeability of endothelial glycocalyx, an effect that is already evident at $60 \mathrm{~min}$ after the beginning of hyperglycemia [28]. Indeed, it has been shown that endothelial glycocalyx degradation fragments are detected during PUUV infection [30], as well as a large number of other markers of endothelial damage, including fibrinogen, von Willebrand factor (vWF), Ddimer, plasma prothrombin fragments $(\mathrm{F} 1+2)$, tissue plasminogen activator (tPA) and IL-6 [31-34]. An increased platelet consumption on the endothelium is considered to be the mechanism of thrombocytopenia in hantavirus infections [1,35]. Thus, any further damage to the endothelium would worsen thrombocytopenia.

In addition to serving as a link between capillary leakage and coagulation, damage to the glycocalyx may interfere with its role as a regulator of inflammation via the capturing of cytokines. Cytokine storm is a well-known finding in hantavirus infections. Plasma levels of IL-1 $\beta$, IL-6, IL-1Ra and TNF- $\alpha$ are clearly elevated in acute PUUV infection and urinary IL-6 excretion is associated with the amount of proteinuria of the disease [34,36]. A plausible explanation is that hyperglycemia-contributes to the viral infection induced endothelial damage, resulting in more severe thrombocytopenia, inflammation and capillary leakage.

Diabetes predisposes to AKI. Interestingly, even transient hyperglycemia has been associated with AKI in clinical and experimental settings, the most prominent damage appearing in the renal tubules $[8,9,37]$. PUUV infects renal tubular cells and acute tubulointerstitial nephritis is detected histologically. It can be speculated that changes in glucose concentration may further aggravate tubulointerstitial injury in PUUV infection [2].

An apparent dose dependency was observed when capillary leakage markers, platelet count, and blood leukocyte count were grouped according to the quartiles of maximum plasma glucose concentration (Figure 1A-E). However, maximum plasma creatinine concentrations were corresponding in the lowest and highest quartiles of maximum plasma glucose concentration (Figure 1F). This discrepancy may be related to impaired gluconeogenesis in the injured proximal tubular cells of the kidney. During fasting conditions, and even under situations of stress, gluconeogenesis in the kidney produces up to $40 \%$ of the systemically available glucose [38]. Ischemia reperfusion injury has been found to impair gluconeogenesis in the kidney, a mechanism that was not fully compensated for by the liver [38]. Another possible explanation is that during AKI, anorexia, nausea, and vomiting may have affected the glucose levels. Altogether, the relation between plasma glucose concentration and AKI is complex.

The present study is observational. The measurements of plasma glucose concentrations were based on clinical relevance instead of systematic sampling. A prospective study is needed to confirm the present results. However, our results are supported by previous findings demonstrating that viral infections can affect glucose metabolism [18,20-22], and that both infection and plasma glucose concentration may contribute to the pathogenesis of capillary leakage, thrombocytopenia and AKI $[8,9,27,28]$. Therefore, subtle changes in plasma glucose level in acutely ill patients serve as biomarkers of disease severity in PUUV infection. The present study only included hospital treated patients. Whether the results are applicable to those with a mild disease could not be addressed.

\section{Conclusions}

We have described here a novel finding that plasma glucose levels relate to the clinical, laboratory and radiological markers of increased capillary leakage, thrombocytopenia, inflammation, and AKI in PUUV infection. Further studies are needed to explore both the mechanism of hyperglycemia and the possible pathophysiological role of plasma glucose behind these findings. 
Supplementary Materials: The following are available online at https: / www.mdpi.com/article/ 10.3390/v13061177/s1. Tables S1-S7: The results of multivariate linear regression analysis with maximum plasma glucose concentration, BMI, age and sex as independent variables and disease severity parameters ad dependent variables.

Author Contributions: Conceptualization, J.T. and J.M.; methodology, J.T. and J.M.; software, J.T. and I.H.P.; validation, J.T., J.M. and H.H.; formal analysis, J.T. and H.H.; investigation, J.T., J.M. and S.M.; resources, J.M., A.V.; data curation, J.T.; writing—original draft preparation, J.T.; writing-review and editing, J.T., J.M., I.H.P., S.M., T.S., A.V., H.H.; visualization, I.H.P.; supervision, J.M. and A.V.; project administration, J.T.; funding acquisition, J.M., A.V. All authors have read and agreed to the published version of the manuscript.

Funding: This study was supported by the Competitive State Research Financing of the Expert Responsibility Area of Tampere University Hospital under grant numbers 9X033 and 9V040 (J.M.), Sigrid Jusélius Foundation under grant number MS568 (A.V. and J.M.), Tampere Tuberculosis Foundation under grant number MS759 (J.M.), Academy of Finland under grant number 321809 (T.S.), and Magnus Ehrnrooth Foundation (A.V.).

Institutional Review Board Statement: The study with its' extensions was conducted according to the guidelines of the Declaration of Helsinki, and approved by the Ethics Committee of the Tampere University Hospital (study codes 97166, 99256, R04180, R15007 and R09206).

Informed Consent Statement: Informed consent was obtained from all subjects involved in the study.

Data Availability Statement: Original data is available as supplementary material.

Acknowledgments: The skillful assistance of Katriina Ylinikkilä and Eini Eskola is greatly appreciated.

Conflicts of Interest: The authors declare no conflict of interest. The funders had no role in the design of the study; in the collection, analyses, or interpretation of data; in the writing of the manuscript, or in the decision to publish the results.

\section{References}

1. Vaheri, A.; Strandin, T.; Hepojoki, J.; Sironen, T.; Henttonen, H.; Mäkelä, S.; Mustonen, J. Uncovering the mysteries of hantavirus infections. Nat. Rev. Genet. 2013, 11, 539-550. [CrossRef]

2. Mustonen, J.; Mäkelä, S.; Outinen, T.; Laine, O.; Jylhävä, J.; Arstila, P.T.; Hurme, M.; Vaheri, A. The pathogenesis of nephropathia epidemica: New knowledge and unanswered questions. Antivir. Res. 2013, 100, 589-604. [CrossRef]

3. Mustonen, J.; Partanen, J.; Kanerva, M.; Pietilä, K.; Vapalahti, O.; Pasternack, A.; Vaheri, A. Genetic susceptibility to severe course of nephropathia epidemica caused by Puumala hantavirus. Kidney Int. 1996, 49, 217-221. [CrossRef] [PubMed]

4. Capes, S.E.; Hunt, D.; Malmberg, K.; Gerstein, H.C. Stress hyperglycaemia and increased risk of death after myocardial infarction in patients with and without diabetes: A systematic overview. Lancet 2000, 355, 773-778. [CrossRef]

5. Krinsley, J.S. Association Between Hyperglycemia and Increased Hospital Mortality in a Heterogeneous Population of Critically Ill Patients. Mayo Clin. Proc. 2003, 78, 1471-1478. [CrossRef] [PubMed]

6. Zhu, L.; She, Z.-G.; Cheng, X.; Qin, J.-J.; Zhang, X.-J.; Cai, J.; Lei, F.; Wang, H.; Xie, J.; Wang, W.; et al. Association of Blood Glucose Control and Outcomes in Patients with COVID-19 and Pre-existing Type 2 Diabetes. Cell Metab. 2020, 31, 1068-1077.e3. [CrossRef]

7. Wang, S.; Ma, P.; Zhang, S.; Song, S.; Wang, Z.; Ma, Y.; Xu, J.; Wu, F.; Duan, L.; Yin, Z.; et al. Fasting blood glucose at admission is an independent predictor for 28-day mortality in patients with COVID-19 without previous diagnosis of diabetes: A multi-centre retrospective study. Diabetol. 2020, 63, 2102-2111. [CrossRef]

8. Moriyama, N.; Ishihara, M.; Noguchi, T.; Nakanishi, M.; Arakawa, T.; Asaumi, Y.; Kumasaka, L.; Kanaya, T.; Miyagi, T.; Nagai, T.; et al. Admission Hyperglycemia Is an Independent Predictor of Acute Kidney Injury in Patients With Acute Myocardial Infarction. Circ. J. 2014, 78, 1475-1480. [CrossRef] [PubMed]

9. Wang, J.-Y.; Yang, J.-H.; Xu, J.; Jia, J.-Y.; Zhang, X.-R.; Yue, X.-D.; Chen, L.-M.; Shan, C.-Y.; Zheng, M.-Y.; Han, F.; et al. Renal tubular damage may contribute more to acute hyperglycemia induced kidney injury in non-diabetic conscious rats. J. Diabetes Its Complicat. 2015, 29, 621-628. [CrossRef]

10. Tietäväinen, J.; Mantula, P.; Outinen, T.; Huhtala, H.; Pörsti, I.H.; Niemelä, O.; Vaheri, A.; Mäkelä, S.; Mustonen, J. Glucosuria Predicts the Severity of Puumala Hantavirus Infection. Kidney Int. Rep. 2019, 4, 1296-1303. [CrossRef]

11. Paakkala, A.; Mäkelä, S.; Hurme, M.; Partanen, J.; Huhtala, H.; Mustonen, J. Association of chest radiography findings with host-related genetic factors in patients with nephropathia epidemica. Scand. J. Infect. Dis. 2008, 40, 254-258. [CrossRef]

12. Vaheri, A.; Vapalahti, O.; Plyusnin, A. How to diagnose hantavirus infections and detect them in rodents and insectivores. Rev. Med Virol. 2008, 18, 277-288. [CrossRef] [PubMed]

13. American Diabetes Association. 2. Classification and diagnosis of diabetes: Standards of medical care in diabetes-2020. Diabetes Care 2020, 43, S14-S31. [CrossRef] 
14. Scientific Division. Working Group on Selective Electrodes12 IFCC recommendation on reporting results for blood glucose. Clin. Chim. Acta 2001, 307, 205-209. [CrossRef]

15. Kormann, R.; Jacquot, A.; Alla, A.; Corbel, A.; Koszutski, M.; Voirin, P.; Parrilla, M.G.; Bevilacqua, S.; Schvoerer, E.; Gueant, J.-L.; et al. Coronavirus disease 2019: Acute Fanconi syndrome precedes acute kidney injury. Clin. Kidney J. 2020. [CrossRef] [PubMed]

16. Deane, A.M.; Horowitz, M. Dysglycaemia in the critically ill—significance and management. Diabetes Obes. Metab. 2013, 15, 792-801. [CrossRef] [PubMed]

17. Mäkelä, S.; Jaatinen, P.; Miettinen, M.; Salmi, J.; Ala-Houhala, I.; Huhtala, H.; Hurme, M.; Pörsti, I.; Vaheri, A.; Mustonen, J. Hormonal deficiencies during and after Puumala hantavirus infection. Eur. J. Clin. Microbiol. Infect. Dis. 2010, $29,705-713$. [CrossRef]

18. Šestan, M.; Marinović, S.; Kavazovic, I.; Cekinović, Đ.; Wueest, S.; Wensveen, T.T.; Brizić, I.; Jonjic, S.; Konrad, D.; Wensveen, F.M.; et al. Virus-Induced Interferon- $\gamma$ Causes Insulin Resistance in Skeletal Muscle and Derails Glycemic Control in Obesity. Immunity 2018, 49, 164-177.e6. [CrossRef] [PubMed]

19. Rasmuson, J.; Pourazar, J.; Mohamed, N.; Lejon, K.; Evander, M.; Blomberg, A.; Ahlm, C. Cytotoxic immune responses in the lungs correlate to disease severity in patients with hantavirus infection. Eur. J. Clin. Microbiol. Infect. Dis. 2016, 35, 713-721. [CrossRef]

20. Yang, J.-K.; Lin, S.-S.; Ji, X.-J.; Guo, L.-M. Binding of SARS coronavirus to its receptor damages islets and causes acute diabetes. Acta Diabetol. 2009, 47, 193-199. [CrossRef]

21. Kleine-Weber, H.; Schroeder, S.; Krüger, N.; Prokscha, A.; Naim, H.Y.; Müller, M.A.; Drosten, C.; Pöhlmann, S.; Hoffmann, M. Polymorphisms in dipeptidyl peptidase 4 reduce host cell entry of Middle East respiratory syndrome coronavirus. Emerg. Microbes Infect. 2020, 9, 155-168. [CrossRef]

22. Wang, Q.; Fang, P.; He, R.; Li, M.; Yu, H.; Zhou, L.; Yi, Y.; Wang, F.; Rong, Y.; Zhang, Y.; et al. O-GlcNAc transferase promotes influenza A virus-induced cytokine storm by targeting interferon regulatory factor-5. Sci. Adv. 2020, 6, eaaz7086. [CrossRef]

23. Liu, F.; Long, X.; Zhang, B.; Zhang, W.; Chen, X.; Zhang, Z. ACE2 Expression in Pancreas May Cause Pancreatic Damage after SARS-CoV-2 Infection. Clin. Gastroenterol. Hepatol. 2020, 18, 2128-2130.e2. [CrossRef]

24. Kitterer, D.; Artunc, F.; Segerer, S.; Alscher, M.D.; Braun, N.; Latus, J. Evaluation of lipase levels in patients with nephropathia epidemica-no evidence for acute pancreatitis. BMC Infect. Dis. 2015, 15, 286. [CrossRef]

25. Warvsten, A.; Björnfors, M.; Arvidsson, M.; Vaziri-Sani, F.; Jönsson, I.; Olsson, G.E.; Ahlm, C.; Larsson, H.E.; Lernmark, Å.; Nilsson, A.-L. Islet autoantibodies present in association with Ljungan virus infection in bank voles (Myodes glareolus) in northern Sweden. J. Med Virol. 2017, 89, 24-31. [CrossRef] [PubMed]

26. Fevola, C.; Forbes, K.M.; Mäkelä, S.; Putkuri, N.; Hauffe, H.C.; Kallio-Kokko, H.; Mustonen, J.; Jääskeläinen, A.J.; Vaheri, A. Lymphocytic choriomeningitis, Ljungan and orthopoxvirus seroconversions in patients hospitalized due to acute Puumala hantavirus infection. J. Clin. Virol. 2016, 84, 48-52. [CrossRef]

27. Nieuwdorp, M.; Van Haeften, T.W.; Gouverneur, M.C.L.G.; Mooij, H.L. Loss of Endothelial Glycocalyx During Acute Hyperglycemia Coincides With Endothelial Dysfunction and Coagulation Activation In Vivo. Diabetes 2006, 55, 480-486. [CrossRef]

28. Zuurbier, C.J.; Demirci, C.; Koeman, A.; Vink, H.; Ince, C. Short-term hyperglycemia increases endothelial glycocalyx permeability and acutely decreases lineal density of capillaries with flowing red blood cells. J. Appl. Physiol. 2005, 99, 1471-1476. [CrossRef] [PubMed]

29. Chelazzi, C.; Villa, G.; Mancinelli, P.; De Gaudio, A.R.; Adembri, C. Glycocalyx and sepsis-induced alterations in vascular permeability. Crit. Care 2015, 19, 26-27. [CrossRef]

30. Connolly-Andersen, A.-M.; Thunberg, T.; Ahlm, C. Endothelial Activation and Repair During Hantavirus Infection: Association with Disease Outcome. Open Forum Infect. Dis. 2014, 1, ofu027. [CrossRef]

31. Laine, O.; Mäkelä, S.; Mustonen, J.; Helminen, M.; Vaheri, A.; Lassila, R.; Joutsi-Korhonen, L. Platelet ligands and ADAMTS13 during Puumala hantavirus infection and associated thrombocytopenia. Blood Coagul. Fibrinolysis 2011, 22, 468-472. [CrossRef]

32. Strandin, T.; Hepojoki, J.; Laine, O.; Mäkelä, S.; Klingstrom, J.; Lundkvist, Å.; Julkunen, I.; Mustonen, J.; Vaheri, A. Interferons Induce STAT1-Dependent Expression of Tissue Plasminogen Activator, a Pathogenicity Factor in Puumala Hantavirus Disease. J. Infect. Dis. 2016, 213, 1632-1641. [CrossRef] [PubMed]

33. Laine, O.; Mäkelä, S.; Mustonen, J.; Huhtala, H.; Szanto, T.; Vaheri, A.; Lassila, R.; Joutsi-Korhonen, L. Enhanced thrombin formation and fibrinolysis during acute Puumala hantavirus infection. Thromb. Res. 2010, 126, 154-158. [CrossRef]

34. Outinen, T.K.; Mäkelä, S.M.; Ala-Houhala, I.O.; Huhtala, H.S.; Hurme, M.; Paakkala, A.S.; Pörsti, I.H.; Syrjänen, J.T.; Mustonen, J.T. The severity of Puumala hantavirus induced nephropathia epidemica can be better evaluated using plasma interleukin-6 than C-reactive protein determinations. BMC Infect. Dis. 2010, 10, 132-138. [CrossRef]

35. Strandin, T.; Mäkelä, S.; Mustonen, J.; Vaheri, A. Neutrophil Activation in Acute Hemorrhagic Fever With Renal Syndrome Is Mediated by Hantavirus-Infected Microvascular Endothelial Cells. Front. Immunol. 2018, 9, 2098. [CrossRef] [PubMed]

36. Mäkelä, S.; Mustonen, J.; Ala-Houhala, I.; Hurme, M.; Koivisto, A.-M.; Vaheri, A.; Pasternack, A. Urinary excretion of interleukin-6 correlates with proteinuria in acute Puumala hantavirus-induced nephritis. Am. J. Kidney Dis. 2004, 43, 809-816. [CrossRef] 
37. Mendez, C.E.; Der Mesropian, P.J.; Mathew, R.O.; Slawski, B. Hyperglycemia and Acute Kidney Injury During the Perioperative Period. Curr. Diabetes Rep. 2016, 16, 10. [CrossRef]

38. Legouis, D.; Ricksten, S.-E.; Faivre, A.; Verissimo, T.; Gariani, K.; Verney, C.; Galichon, P.; Berchtold, L.; Feraille, E.; Fernandez, M.; et al. Altered proximal tubular cell glucose metabolism during acute kidney injury is associated with mortality. Nat. Metab. 2020, 2, 732-743. [CrossRef] [PubMed] 